\title{
EDITORIAL
}

\section{Border Crossings in Language \\ Intercultural Encounters at the Crossroads of Disciplines}

\author{
Marie-Noëlle Guillot, University of East Anglia
}

This special issue brings together papers with a different focus and different outlooks: translation and cognitive processing, intercultural impoliteness, transnationals and impressions at work, intercultural parenting manuals, video games and localisation. All are concerned with intercultural communication, in its manifestations and impacts in different contexts. All are interdisciplinary in their approach, in their own distinctive ways.

These are defining features of this special issue of Multilingua, as they are of the journal's aims. The volume has two interrelated goals: to promote synergies between disciplines with an overriding interest in the cross-linguistic study of language and to stimulate the interplay between them through reciprocal interrogation of methodologies and findings. It is also mindful of the impact agenda now vigorously pursued in research in most contexts, and intent on capitalizing on the consequent drive to interface theory and practice. The volume's main sites of interrogation and interaction are cross- and intercultural pragmatics and translation, with contributions at the junction of socio-cognitive and interactional pragmatics, cognitive linguistics, linguistic typology, discourse analysis, translation studies, cultural studies. 
The case for interdisciplinarity in approaching language from a cross-linguistic and cross-cultural perspective has been made before, but these domains in particular have remained oddly resistant to the cross-fertilization of their research and methodologies. Creating a space for their interaction and mutual enrichment has been a main raison d'être of the Cross-cultural Pragmatics at a Crossroads (CCP) conferences at the University of East Anglia (UK). ${ }^{1}$ The papers in this special issue are derived from plenary papers from the third in the series, CCP III - Impact: Making a Difference in Intercultural Communication (26-28 June 2013).

The series has brought together under the broad umbrella of cross-cultural pragmatics researchers from domains which are particularly sensitive to cross-cultural issues and has sought to promote an interchange of practices, ideas and theoretical approaches, with the overall aim of exploring key practical and theoretical concerns associated with communication across language and culture boundaries. This commitment has been reflected in the choice of plenary speakers representing complementary theoretical perspectives or approaches, different research contexts, and different languages. It is manifest in the papers in this volume, by leading researchers in Australia, France, Spain, Ireland/Japan and the US and their work encompassing cognitive processing from translational and interactional pragmatics perspectives, intercultural and socio-pragmatics, translation and globalisation, translation and contrastive rhetoric, contrastive translation and psycholinguistics, discourse analysis and social and professional discourse, and

Like CCP events generally, the volume is a response to now pervasive calls for interor multi-disciplinarity in investigating language and addressing the challenges of communication across languages and cultures. The call is made prominently in Kotthoff and Spencer-Oatey (2007) and Spencer-Oatey and Franklin (2009). It is also in evidence in Sharifian and Jamarani's recently edited volume Language and Intercultural Communication 
in the New Era (2013) where it underpins most contributions. Greater cooperation between studies in intercultural communication and approaches to translational action has also been advocated, most notably by House and colleagues (in Bührig, House and ten Thije 2009, for example). Mutual engagement of these domains has been limited, however, despite the fastincreasing prominence of mediation in all spheres of human activity in a global context and its potential to illuminate studies in communication and language processing. The potential of intercultural pragmatics and contrastive typological approaches to inform translation studies debates, notably in their application to new contexts (conflict negotiation or legal or medical contexts, crowdsourcing, for example) is likewise yet to be capitalized upon.

This volume is intended as a step towards closer integration of these domains. Its five articles, by Ana Rojo, Istvan Kecskés, , Lynda Yates, Patricia Von Münchow andMinako O'Hagan , embody interdisciplinarity in different guises across a spectrum of theoretical and practical concerns. They illuminate current debates in their own ways, yet converge on, and highlight, generic themes and changing orientations, about notions of culture, for example, and the multifarious morphing of the mono and the intercultural in communication.

The two opening chapters (Rojo, Kecskés serve as a conceptual preamble, with each approaching language in use through cognitive processing, but from the different perspectives of translation and intercultural pragmatics, and translational processes and impoliteness respectively. Subsequent chapters take up these threads, first with two contributions on crossand intercultural communication and representation (Yates, Von Münchow), with professional and more broadly societal impact respectively, and, like the first two, distinct angles of approach and focus (transnational perceptions at work and their management, interdiscursivity in intercultural parenting discourse). The last chapter (O’Hagan) shifts back to the translational and introduces new sites and modalities of intercultural interaction, with (videogames) modern digital entertainment as a locus of intercultural exchange. All are 
underpinned by the ever-increasing pervasiveness of the forms of cross- or intercultural communication they engage with, and the urgent need therefore to develop a better understanding of their underpinnings, and of their emergent dynamics.

In the first chapter, the case for interdisciplinary is made from a still unusual but increasingly productive angle. Rojo applies her cognitive linguistic approach to the study of translation, with a review of a range of empirical studies combining both, and the objective of demonstrating the mutual benefits to be derived from these two fields for their respective research. The argument is driven by the acknowledgment of translation's omnipresence and social relevance in the globalised world, but its still elusive nature as an inherently complex process at the interface of the linguistic, the cognitive, the sensory-motor, down to prevailing norms in given societies and translators' own (cognitive) abilities or individual traits. It is framed by Rojo's rebuff of the condescending attitude of other cognitive disciplines towards translation and its relevance to their research, and her ambition to redress the balance of interest.

Under different headings that include translation as mental representation, its impact on comprehension, translation and metaphorical language, its emotional impact, debates about equivalence in the light of cognitive linguistics and the impact of personality on translation, Rojo takes us on a journey of empirical discovery that illustrates some of the central questions that translation studies has attempted to answer with other cognitive science disciplines, to account for translation as a fundamentally embodied, situated and dynamic process of cognition and meaning. She observes in conclusion that the interdisciplinary turn in modern translation studies has "prepared the ground for implementing more experimental, sophisticated methods". Research instruments from empirically oriented disciplines and triangulation of research methodologies are giving studies of translation greater scientific rigor. They are opening up new avenues for the investigation of the multifaceted process of 
translation: for defining the factors that condition the translation activity and translators' work, and for describing the potential impact that translation has on communication and language processing generally.

This two-way relationship is illustrated with studies using eye-tracker technology to illuminate translation processes with information about cognitive effort involved across tasks, or probing the translation of metaphorical language or the relationship between emotions and translation. Cognitive linguistics can inform translation studies, with evidence, for example, of differences in the conceptualisation of topics and differential impact of metaphors for source and target audiences (e.g. Rojo 2011). Conversely translation studies provides insights into the impact translation may have on target contexts: by translating metaphors literally, a documented preferred strategy in translation from English to Spanish, for example, translators may thus "be enlarging the target conceptual world and contributing to intercultural standardisation of culture-specific items and cognitive patterns". Neurophysiological and other types of empirical tests demonstrate that positive and negative emotions may trigger different processing and translation styles, or again that the objectivity and neutrality principles relied on to promote bias-free audio-descriptions of factual information may have the opposite effect in art films, thus pointing to the need to adapt styles and practices to accommodate differences (Ramos and Rojo [submitted]).

This interplay is also central to the reassessment of traditional debates about formal vs. dynamic equivalence and the tensions between form and meaning in translation, illustrated at their most acute in forensic and psychological studies of typology-based translation patterns and their impact - literally a matter of life and death in some contexts (e.g. police interviews and witness reports, law courts). The impact of translators' ideological stances on the translation process is likewise a sensitive and largely unexplored issue, where 
input from neurological studies, for example, provides a platform to inform our understanding.

In these kinds of studies and their results, Rojo finds ample evidence to warrant a fundamental change in attitude. Translation research is currently at a vantage point, she contends, from which it can contribute to widening our knowledge of cognitive processing in bilingual and bicultural contexts. It is time to reverse the one-way relationship in which translation has been the recipient from other humanities or social sciences disciplines, and capitalize on a genuine bi-directional relationship "in which findings from translation studies can be used to improve our knowledge of communication and language processing". Posing the right questions, standardizing research aims and methods and coordinating research effort are critical for bringing translation closer to other cognitive science disciplines.

$\mathrm{Bi} /$ multilingual and bi/multicultural mindsets are also a main locus of exploration in the research recapitulated in the next chapter, now from a socio-cognitive end, and there too seen to inform our generic understanding of communication processes and practices. In this second contribution, Kecskés brings us back to more familiar domains of pragmatics, with a new twist. He deals with intercultural impoliteness, a relatively recent domain of enquiry in pragmatics research, but ubiquitous as a by-product of the ever greater occurrence of intercultural encounters today. Kecskés notes that impoliteness research has been dominated by intra- and cross-cultural views, and context dependency as an underlying principle: research on politeness/impoliteness has applied mainly to single languages or cross-cultural comparisons, and in both cases recognized existing ground and conventionalized context as determinant features. How speakers do politeness/impoliteness in interactions in which they are conversing in a language other than their mother tongue is yet to be dependably explored. Impoliteness, in particular, is still largely uncharted territory. It is argued here to involve quite different processes. 
Kecskés harnesses existing politeness/impoliteness theories and his own sociocognitive pragmatics approach to this end, and revisits in the process the discoursal turn, in its shift from abstract theoretical concepts of politeness/impoliteness to members' evaluative practices in their everyday discourse, and emphasis on individuals and communities of practice (from Wenger 1998). Interlocutors with different L1s can hardly be described as "social communities", in the sense that underpins some definitions of impoliteness, and within which communicative acts may be perceived as purposefully offensive. They can, on the other hand, be considered communities of practice, for which (emergent) norms of appropriateness can be identified, albeit on quite different grounds than in L1. From an L1 perspective, context is all in current thinking: no act is inherently impolite, and all hinges on the situational context and speakers with a same mother tongue relying on shared knowledge about context. There is no such shared knowledge in intercultural communication, and the playing field for politeness/impoliteness is thus inherently different. These are the basic observations that underpin Kecskés’ discussion.

From his socio-cognitive angle, politeness/impoliteness "is both constituted in the communicative process through on the spot evaluations and decisions, and constitutive of the communicative process through expectations and norms". The actual situational context is viewed through prior context, and this creates a third space for emergent politeness/ impoliteness. The characterisation of intercultural impoliteness is thus dependent on our understanding of a complex interplay of prior context and actual situational context in meaning construction and comprehension. Critically, it should take into account the potentially profound effect on the processing of politeness/impoliteness in actual situational contexts of non-native speakers' demonstrated propensity to base their interpretation of utterances on their compositional meaning (House 2002, 2003, Kecskés 2007 and others), i.e. of the priority of semantic analyzability in non-native speakers' constructions of 
impoliteness. In "why don’t you sit down"/ "because you didn't tell me to", for example, the first utterance is not responded to as the invitation to sit down it can be, by the standards of English. It is treated literally instead, as a request for an explanation of non-compliance, on the basis, from a non-native speaker perspective, of (possibly different) pre-existing norms and conventions, evidenced in the lack of sensitivity to the figurative meaning of the question and the culture-specific conceptual load it carries in English. This is also an example of native 'mock' impoliteness, an opportunity for Kecskés to disagree with context-dependency driven explanations that in such cases the actual situational context is neutralized: what is neutralised, for Kecskés, is prior context, and generic culture-bound constraints. The unwitting neutralization of the culture-bound in non-native practices and the standardization of culture-specific items and cognitive patterns that Rojo observes in the translation of metaphors are no doubt governed by different processes. The echo that they find in one another is nonetheless intriguing, and an incentive for further interdisciplinary enquiry into what they may share and their cumulative impact in an increasingly intercultural world.

There are as yet no large datasets to analyze intercultural impoliteness on its own terms. That is the next step down the research line for which Kecskés makes a case with his review of issues, with an invitation to revisit debates on context-dependency vs. generic cultural norms or constraints. These debates clearly have ramifications well beyond (im)politness and pragmatics.

The next set of contributions deals with specific intercultural concerns, with a shift to representation, in its manifestations and its impacts, as experienced by transnationals in the workplace (Yates) and conveyed in intercultural parenting manuals (Von Münchow). Here again, interdisciplinary allegiances are harnessed to different ends - tackling actual problems of intercultural communication, and developing insights into the dynamics of societal interculturality. Here again converging questions arise, about the shifting boundaries of 
notions of culture, but also about the need to recognize what binds them together in otherness for tackling in practice the challenges of intercultural encounter, and understanding the trajectories of intercultural journeys.

Yates addresses this head on with the research accounted for in her paper, on professionals working in cultures and languages in which they did not undertake their professional training - transnationals -, and the communication challenges they face in the workplace, even with high levels of proficiency. She examines two professions in which communication skills are critical and demands exacting, child care and medicine, in the context of Australia, country of migration and home to many transnationals. There, as in other comparable contexts, there is a great deal at stake, for individuals and for host environments: potential long term barriers to employment at levels commensurate with skills, downward occupational mobility, personal frustration, waste of human capital and loss of national productivity. Yates focuses on the largely invisible and most elusive aspects of potential miscommunication and attendant negative impressions at work, that is "pragmatic understandings underlying communicative expectations in the workplace, how they relate to particular professional values, and how these are expressed through talk at work". One main issue is for transnationals to recognize that languages use different pragmatic resources for mapping force onto form. Another is to recognize the sociocultural values that underlie the way language is used across the broad spectrum of functions, transactional and interactional, with which they are called upon to engage at work: profession-specific talk but also the small talk of socialisation, its humour, expletives and so on. As culture and these values are notoriously difficult to pin down, the conundrum is to do them justice in their dynamism and heterogeneity, without oversimplification and stereotyping, and to "teach" them accordingly. But this Yates argues, must be done, contentious though it may be, or as reluctant or unprepared as teachers may feel about dealing with the sensitive nature of what is involved 
(deeply held personal values, potential and unhelpful/wanton stereotyping). Finding ways of offering appropriate language instruction "responsive to the hybridity, diversity and dynamism of our contemporary multicultural society, but also focused on the skills and knowledge that can also help newly-arrived immigrants acquire the communicative skills they need" is imperative for curbing underemployment and downward mobility for many qualified and experienced transnationals.

That has been Yates's project, and the object of the empirical studies presented here, in the theoretical questions they raise and in the outcomes of their incursions into specialised domains, linguistic, cultural, ideological. The aim has been to generate evidence-based materials in situ for teaching immigrants to Australia, here trainee early childhood teachers and internationally-trained graduates qualified in medicine in another language. The methodology is compelling, as is the evidence gathered and the "pragmatic sleuthing" pedagogy advocated. The features identified across both contexts unravel the knot of principles and values enacted in interactive practices - orientation to inclusion, mutual respect, responsabilising in childcare, for example - and their pragmalinguistic manifestation in interpersonal strategies, tailoring to lay audience, informality, humour etc. in the people and patient-centred education and care systems of Australia. They point to value and pragmalinguistic gaps in awareness and practices, in particular for trainees from cultures with a more authoritarian and distant stance, to patients in medical care, for example. Uptake in pragmatic learning is a matter of choice, however, as Yates takes care to stress, and teaching itself unrealistic: the role of instruction is to promote pragmalinguistic and sociopragmatic empowerment and help adult immigrants and other newcomers to identify how cultural values play out in interaction and negotiate their identities on their own terms.

Working with notions of culture is a challenge, conceptually and operationally, Yates concludes. Its impact on sociopragmatic expectations and pragmatic behaviour cannot be 
ignored, however: "While we certainly need to embrace the emergent and constructed dimensions of culture and guard against objectification and oversimplification, this should not entail a rejection of its powerful role in providing a largely invisible framework within which communities produce, reproduce and interpret meaning”.

This conceptual point, central in Yates and broached in Kecskés, also surfaces in Von Münchow. With her contribution, the ground shifts from the professional to the more broadly societal. The intercultural communication platform is also now shared with another set of interdisciplinary partners, in a distinctive domain of application - intercultural parenting books, that is books created under a double cultural influence by authors raised in one country, before spending an extending period of time in another. There is convergence on critical themes, however, and echoing interrogations.

In her studies, here of Franco-American intercultural parenting books (FAIPBs), Münchow pushes the boundaries of research into new discursive genres, that typically embody new forms of intercultural encounters and influences and their ambivalent manifestations. Her research itself is intercultural in its underpinnings. The approach she has pioneered, cross-cultural discourse analysis (CCDA), interfaces French discourse analysis, text linguistics and cross-cultural studies, with the long term aim of developing an understanding of "discursive cultures", as manifest in, and projected by, social representations circulating within communities about social objects themselves, and about the discourse about these objects. It is informed by intercultural communication and education (Bennett and Bennett 2004, Byram 2008) and critical discourse analysis (Reisigl 2009), and otherwise more broadly by studies in the sociology of the family, the sociology of education, history and feminist discourse analysis. The method involves identifying linguistic markers and traces of discursive operations in data belonging to a specific discourse genre and inferring hypotheses on social and cultural representations. The main data in this case are 
three intercultural parenting books by authors originally from the US and Canada but based in France during their childrearing time, set against monocultural parenting books with three French and three American bestselling titles.

Von Münchow's account of the features of FAIPBs' discursive genre and complementary analyses reflect interesting sets of positionings, at best ambivalent, but in any case reflecting deep-seated cultural notions and beliefs, as in Yates.

FAIPBs are identified as a hybrid genre, in an interdiscursive network comprising various other types (parenting guide books, parenting memoirs, travel memoirs, intercultural guide books, lifestyle guidebooks, etc.), with a public visibility that makes their features and impact worthy of attention. The intercultural component as expressed in the data through different linguistic traces of cognitive operations is shown to pertain to various processes: (so called) "reverse astonishment", cognitive processes of intercultural discovery in several stages, e.g. from incomprehension to understanding of French children's “astonishing” (good) behaviour (for FAIPB authors), cognitive frame shifts (to the perspective of the other culture), invalidation of stereotypes trying to fight off cultural defense by their readers, collectivisation vs. particularisation, that in the end still tend to construct dualistic "usthem"comparisons. By contrast with negative discriminatory discourse, the us-them/FrenchAnglophones comparison turns out to be positive for the French and negative for the NorthAmerican child-rearing style. On a more implicit level, however, French parents are depicted as "being acted upon" by their culture, in contrast with American parents' agency in their individual approach and conscious choice of strategies, thus introducing negative discrimination by another door, in a mixture of ethnorelative and ethnocentric discursive procedures.

By confronting FAIPB representations with representations explicitly or implicitly constructed in French and American parenting books, Von Münchow then exposes "hidden 
information" in the form of implied or presupposed knowledge and beliefs. She identifies further ambivalences and tensions resulting from the co-influence in FAIPBs of different sets of representations and different discursive cultures: FAIPB authors may well advocate a shift towards an alternative parenting (French parent-centred) model, but still rely on the argumentative procedures of their child-centred discursive culture, thus demonstrating the prevailing influence of initial representations, and the problematic relationship between mental and social representations in the analysed data - echo from a different angle of some of Kecskés and Yates' observations. While the parenting agenda can reasonably be assumed to be the driving concern for authors, in practice the intercultural aspects turns out to be pervasive, far more than authors themselves may even be aware of: cultural membership may be produced in interaction, notes Von Münchow, but it is certainly mainly shaped by prior interaction, throughout life, as highlighted in earlier contributions from their own perspectives.

To the question raised by way of conclusion of whether cross-cultural research informs intercultural studies, or whether neither is worth conducting and we should instead problematize or abolish the notion of culture, as some approaches to intercultural discourse contend, Von Münchow's answer is unequivocal, unlike her data and the observations it produces: cross-cultural studies inform intercultural research, in particular by bringing out "hidden" information in the latter, in the case of intercultural parenting books at least. But there are no clear boundaries between monocultural and intercultural communication; intercultural or discriminatory components in datasets should not be assumed and require investigation by analysis. This cautionary advice extends to the other studies reported here.

New forms of intercultural encounters are also central in the last contribution in the volume, but here involve technology and its new frontiers. O'Hagan takes us back to translation, and turns to intercultural communication in the digital age, to address the 
challenges that videogames pose for translation as a new form of intercultural communication and technology-mediated experience.

She echoes Rojo in advocating the expansion of the disciplinary scope of translation studies, now with application to the significant cultural interface that video games have become with their widespread dissemination worldwide. They call into question the boundaries of what is understood to be translation, and also the type of facilitation performed via a technological artefact for intercultural communication. Translation studies perspectives are combined with the theoretical framework of the critical theory of technology (CTT), to argue that game localisation "is eliciting something new about the role of translation in forging intercultural communication in the digital age".

Video game localisation is a relatively new practice representative of translation in the digital age and involves digital content subject to translation. Software localisation is generally described as intended to deliver products with the same or equivalent "look and feel" of similar locally available products, which means that their presentation and functionality must be adapted to local conventions (Fry 2003: 5). While localisation involves distinct and new processes that warrant specific training, it is not clearly delineated from the concept of translation and has tended to keep to a narrow view of translation as strictly interlingual operations, failing to recognize it as firmly mapped into both (inter)cultural and linguistic space in its theory and practice. But game localisation involves far more than mechanical transcoding and poses deeper cultural challenges. It has shifted the industry's perceptions, and challenged translation studies to attend to what is new in how cultural issues manifest themselves in game software, and here, too, look beyond its own disciplinary bounds to illuminate its own processes.

Specific issues are shown to stem from a number of factors, relating to games being cultural as well as technical artefacts, primarily designed for entertainment purposes 
prioritizing users' (affective) engagement, part of a strong game culture that has both global and local elements and a site for fan work associated with fan translation or translation hacking and critiquing. The nature of games and their inbuilt constraints, also including features like on-screen space limitations, country-specific age ratings and possible sociocultural, legal or ideological restrictions associated, for example, with the depiction of sex, violence or religions, call for appropriate strategies in adapting them to other locales, and for "culturalisation" to accommodate their primarily cultural nature and address possible "intercultural dissonance" (Edwards 2012). Examples include how to deal with gender and sexuality issues, accommodation of transgender characters from Japanese games, dealing with humour, etc.

The transformations generated by culturalisation are designed to immerse end users maximally into the imagined game world by retaining a suspension of disbelief, notes O'Hagan. But they are far from innocent, she argues in conclusion, and "while translation studies offer explanations about the complex interaction of influencing factors on translation, modern digital artefacts such as interactive games demand a further expansion of theoretical bases to analyse and capture the fundamental shift unfolding in the way intercultural communication is mediated by translation on a technological platform". With the framework of CCT and the functionalist approaches and cultural turn in translation studies that underpin her argument, and her casting of game localisation at the junction of technology and culture, O’Hagan provides us with a platform to do just that.

This special issue is interdisciplinary because it brings together articles from experts in different fields plying their trades with different applications. It is interdisciplinary because each contribution is itself turning to different disciplinary fields to make sense of the complex interwoven sets of underpinning assumptions and performed practices in evidence in mutable intercultures, the world we inhabit today. Few of us will perhaps have the breadth of 
expertise to feel equally at home or at one with the theories, methodologies or subjects represented in this volume, but all of us it is hoped will recognize their overarching concerns and find in them cause to revisit our own in a new light.

\section{Notes}

The first Cross-cultural Pragmatics at a Crossroads Conference was held at the UEA 3-4 November 2006 on the theme of "Speech Frames and Cultural Perceptions". The second, on the theme of "Linguistic and Cultural Representations across Media", was held 29 June-01 July 2006 (See Guillot 2010, 2012 for resulting publications) (available at http://journals.cambridge.org/action/displayIssue?decade=2010\&jid=JFL\&volumeId=20\&iss ueId=01\&iid=7155120; http://www.tandfonline.com/toc/rmli20/12/4).

\section{Acknowledgements}

My grateful thanks to by István Kecskés, Minako O’Hagan, Ana Rojo, Patricia Von Münchow and Lynda Yates for generously contributing their articles to this special issue, and to my colleagues from the School of Language and Communication Studies at the University of East Anglia for their support with the conference that gave rise to this publication. 
We also extend our gratitude to the Cultural Service of the French Embassy in the United Kingdom and the Great Britain Sasakawa Foundation for their generous sponsorship of CCP III, the third Cross-cultural Pragmatics Conference held at the University in Norwich (UK) 26-28 June 2013 on the theme of Impact: Making a Difference in Intercultural Communication.

\section{References}

Bennett, Janet M. \& Milton J. Bennett. 2004. Developing intercultural sensitivity. An integrative approach to global and domestic diversity. In Daniel Landis, Janet M. Bennett \& Milton J. Bennett (eds.), Handbook of intercultural training, 147-165. 3rd edn. Thousand Oaks, London: Sage.

Byram, Michael. 2008. From foreign language education to education for interculturalcitizenship. Essays and reflections. Clevedon: Multilingual Matters.

Edwards, Kate. 2012. Culturalization of game content. In Heather Chandler \& Stephanie O’Malley Deming, The game localization handbook (2nd ed.), 19-34. Sudbury, MA; Ontario \& London: Jones \& Bartlett Learning.

Fry, Deborah. 2003. The localization industry primer ( $2^{\text {nd }}$ edn. Revised by Arle Lommel). http://www.immagic.com/eLibrary/ARCHIVES/GENERAL/LISA/L030625P.pdf (accessed 15 March 2014).

Guillot, Marie-Noëlle (ed.). 2012. Intercultural communication at a theoretical and methodological crossroads: cultural and media interfaces. Special issue of Language and Intercultural Communication 12 (4). 
Guillot, Marie-Noëlle (ed.). 2010. Cross-cultural Pragmatics - Pragmatique comparée à la croisée des chemins: cadres du discours et perceptions culturelles. Journal of French Language Studies 20.1: Special Cross-cultural Pragmatics Volume. Cambridge: Cambridge University Press.

House, Juliane. 2002. Developing pragmatic competence in English as a lingua franca. In Lingua Franca Communication, Knapp Karlfried and Christiane Meierkord (eds.), 245267. Frankfurt am Main: Peter Lang.

House, Juliane. 2003. Misunderstanding in intercultural university encounters. In Juliane House, Gabriele Kasper \& Steven Ross (eds.), Misunderstanding in social life: Discourse approaches to problematic talk, 22-56. London: Longman.

Kecskés, István. 2007. Formulaic language in English lingua franca. In Explorations in pragmatics: linguistic, cognitive and intercultural aspects, István Kecskés\& Laurence R. Horn (eds.), 191-219. Berlin/New York: Mouton de Gruyter.

Kotthoff, Helga \& Helen Spencer-Oatey (eds.). 2009. Handbook of intercultural communication. New York: Mouton de Gruyter.

Ramos, Marina and Ana Rojo. Submitted. "Feeling" audio description: Exploring the impact of AD on emotional response. Translation Spaces.

Reisigl, Martin. 2009. Discrimination in discourse. In Helga Kotthoff \& Helen SpencerOatey (eds.), Handbook of intercultural communication, 365-394. New York: Mouton de Gruyter.

Rojo, Ana. 2011. Distinguishing near-synonyms and translation equivalents in metaphorical terms: crisis vs. recession in English and Spanish. Annual Review of Cognitive Linguistics 9. 283-214. 
Sharifian, Farzad \& Maryam Jamarani (eds.). 2013. Language and intercultural communication in the new era. London: Routledge.

Spencer-Oatey, Helen \& Peter Franklin. 2009. Intercultural interaction: a multidisciplinary approach to intercultural communication. Basingstoke: Palgrave Macmillan.

Wenger, Etienne C. 1998. Communities of practice: learning, meaning, and identity. Cambridge: Cambridge University Press. 